\title{
INTERATIVIDADE, EXPRESSIVIDADE E ENGAJAMENTO NO NEWSGAME "DE VOLTA A 1964: SUA VIDA EM TEMPOS DE DITADURA"
}

\author{
Lilian Cristina Monteiro França
}

\begin{abstract}
Resumo
Em 2014, uma série de eventos tem marcado os 50 anos do golpe militar no Brasil, com destaque para a revista Superinteressante, que empreendeu a revisão dos fatos por meio do newsgame "De volta a 1964: sua vida em tempos de ditadura". A proposta deste paper é analisar o newsgame considerando-se a sua expressividade, engajamento e experiência proporcionados ao jogador com base nos conceitos desenvolvidos por Frasca (2001), Bogost (2008), Bogost, Ferrari \& Schweizer (2010), lurgel \& Zagalo (2009), Ferrari (2009), Gonçalves \& Zagalo (2010) Zagalo (2012), Sicart (2008), entre outros. A partir da experiência com o jogo foram categorizados os níveis de interatividade e reatividade disponibilizados, de acordo com os possíveis percursos a serem trilhados pelo leitor/jogador. A análise desenvolvida permite verificar até que ponto o exercício de simulação proposto delineia narrativas vinculadas ao perfil editorial da revista e em que medida pode fomentar o debate público.
\end{abstract}

\section{Patavras-chave}

Newsgames; interatividade; expressividade; engajamento

\section{INTRODUÇÃo}

Newsgames resultam do "o encontro entre o jornalismo e os cartoons políticos", escreveu Gonzalo Frasca, pioneiro desenvolvedor, estudioso e criador do termo newsgames. Bogost, Ferrari \& Schweizer (2010: 13) ampliam o conceito de Frasca e definem: “[...]'newsgame' sugere qualquer intersecção entre jornalismo e jogo"'. Para Déda \& Zagalo (2010):

Os Newsgames como assim são denominados, são jogos baseados em notícias jornalísticas que configuram uma nova forma de transmitir um fato mergulhado no campo imersivo dos vídeos Jogos. Esta ferramenta permite criar um modelo de transmissão informativa interativa tornando o jornalismo mais participativo e ainda atuando como uma plataforma móvel de divulgação (Déda \& Zagalo, 2010: 130).

Os newsgames surgem em um contexto marcado pela "gameficação" da sociedade e pelo advento do jornalismo on-line. O processo de "gameficação" da sociedade tem tirado os videogames de sua função de entretenimento para gerar parcerias com diferentes áreas (educação, jornalismo, cinema, entre outras), originando novas formas de 
narrativas que visam atender às expectativas de um público que vem, cada vez mais, acumulando conhecimentos e práticas com jogos eletrônicos. De acordo com o especialista em games lan Bogost (2008: 19), “[...] As pessoas que jogam vídeo game desenvolvem valores, estratégias e abordagens para a prática do jogo em si", os eventos que se desenrolam "dentro" do espaço do game desdobram-se para o cotidiano, produzindo na visão de mundo do jogador. A relação com o vídeo games intensifica-se com o desenvolvimento tecnológico que amplia a verossimilhança e a aproximação com situações reais, favorecendo a imersão no ambiente do jogo.

Ao mesmo tempo, esse mesmo desenvolvimento tecnológico impacta o campo jornalístico, colocando em xeque a sua estrutura tradicional, ancorada na produção de conteúdo impresso e sustentada pelos lucros advindos, sobretudo, da receita publicitária. Em um momento de crise financeira, dos modelos de negócios, dos suportes, da publicidade, do acesso, de relevância, em um ambiente de competitividade em que as empresas precisam não só competir entre si, mas também com a produção jornalística oriunda de sites colaborativos e redes sociais, as empresas jornalísticas abriram-se para a inovação: versões on-line de suas edições, aplicativos específicos para suportes móveis (smartphones e tablets), formação de equipes multidisciplinares e reestruturação da lógica narrativa do conteúdo produzido, esboçando uma "nova mídia".

A colisão entre a mídia tradicional e a nova mídia, como entende Jenkins (2006), acontece numa época de convergência: "Bem-vindo à cultura da convergência , onde as mídias antigas e novas colidem, onde as 'bases' e a mídia corporativa se cruzam, onde o poder do produtor de mídia e o poder do consumidor de mídia interagem de forma imprevisível" saúda Jenkins (2006: 11), que apresenta um novo paradigma para pensar a sociedade, alicerçado na convergência midiática, na cultura participativa e na inteligência coletiva.

Pensar com base nesse novo paradigma é desafiador e demanda uma revisão das certezas que fundamentam e balizam a reflexão teórica, como acontece com os newsgames, estruturas narrativas que unem a seriedade do bom jornalismo ao caráter lúdico dos vídeo games. Com os pés fincados nesse terreno movediço, novo, repleto de conceitos provisórios, mas que já conta com uma vasta literatura, pretende-se, neste paper, analisar o newsgame "De volta a 1964: sua vida em tempos de ditadura", lançado em 1 de abril de 2014, pela revista Superinteressante, data do golpe militar que deu origem a vinte anos de ditadura militar no Brasil.

A partir da experiência com o jogo, e, considerando-se a sua expressividade e engajamento, foram categorizados os níveis de interatividade (linear, hierárquica, de suporte, de simulação, de hiperlinks) e reatividade disponibilizados, de acordo com os possíveis percursos a serem trilhados pelo leitor/jogador. A análise realizada permite verificar até que ponto o exercício de simulação proposto delineia narrativas vinculadas ao perfil editorial da revista e em que medida pode fomentar o debate público e contribuir para uma determinada compreensão dos significados do golpe para o país. 


\section{Apresentando o NEWSGAME "De volta A 1964: SUA VidA EM TEMpos DE DitAdura"}

O ano de 2014 marca os 50 anos do golpe militar que aconteceu no Brasil. O evento recebeu por parte da mídia² uma atenção especial a partir do segundo semestre de 2013, momento em que uma série de eventos passaram a ser pautados, a fim de realizar uma revisão histórica daquele momento crítico para o país. Cada veículo buscou encontrar um meio para discutir um tema que impactou a vida de milhões de brasileiros e mudou os destinos da nação.

Para marcar presença na discussão, a revista Superinteressante optou por produzir conteúdo relativo ao tema no formato de um newsgame, tendência que vem sendo adotada por importantes veículos de mídia no mundo todo. Bogost, Ferrari \& Schweizer (2010), na obra clássica Newsgames: journalism at play, consideram a crise que o jornalismo mundial atravessa e a necessidade de desenvolver novos modelos de negócios e novas linguagens que possam atrair leitores contribui para que o jornalismo adote uma perspectiva inovadora: "[o] jornalismo pode e vai abraçar novos modos de pensar a notícia e novos modos de produção" (Bogost, Ferrari \& Schweizer, 2010: 10).

A Revista Superinteressante, lançada em 1987 pela Editora Abril, com o objetivo de atuar na área de divulgação científica, ganhou a credibilidade do público, passando a ser respeitada como veículo de alfabetização científica, conquistando um público fiel para suas edições impressas e, posteriormente, para a edição digital. Em pesquisa publicada pela ComScore (2014) a revista recebeu 11.482.000 page views, 3.189.000 unique visitors no mês, de uma audiência composta por $55 \%$ de leitores do sexo masculino e $46 \%$, do sexo feminino, com $87 \%$ dos leitores na faixa dos 15 aos 34 anos (36\% deles entre 15 e 19 anos), dos quais $11 \%$ integram a classe A, 61\% a classe B e $27 \%$ a classe C (a classe $\mathrm{D}$ representa apenas 1\% e a $\mathrm{E}$ não tem representação, ০\%).

O perfil da revista atrai a atenção do público jovem, em especial os que cursam os ensinos médio e superior, razão pela qual seus editores têm optado por investir no desenvolvimento de novas linguagens para a divulgação científica, entre elas os newsgames, tornando-se pioneira na criação de jogos de notícias no país. A Superinteressante é editada pelo Núcleo Jovem da Editora Abril e em 2008 lançou o newsgame "CSI — A ciência contra o crime", que obteve muita receptividade, incentivando o investimento no formato. "Filosofighters", "O jogo da Máfia", "A evolução do Movimento", "Corrida Eleitoral", estão entre os mais acessados newsgames da Superinteressante.

O interesse gerado pelos newsgames preparados pelo Núcleo Jovem da editora, dirigido em 2008 por Fred di Giacomo Rocha, responsável por trazer o formato para a revista, tornou-se um interessante filão de mercado, passando a integrar a rotina de produção da Superinteressante desde então. Diante do ambiente criado, o desafio de produzir conteúdo sobre o golpe de 1964 para um público eminentemente jovem, fez com que os editores decidissem construir um newsgame que simulasse algumas das situações

\footnotetext{
${ }^{2}$ Embora não seja o objetivo desta análise, cabe pontuar que no cenário brasileiro alguns veículos de mídia foram considerados como um braço forte da ditadura militar, apoiando o golpe e atuando para garantir a sustentabilidade para o regime, o que torna o tratamento do tema especialmente espinhoso em alguns casos, o que ensejaria uma análise específica acerca do tratamento dado aos 50 anos do golpe pelos diferentes meios de comunicação.
} 
que a população brasileira enfrentou no período, dando origem ao newsgame "De volta a 1964: sua vida em tempos de ditadura" (Figura 1), título que remete ao filme "De volta para o futuro", 1985, dirigido por Robert Zemeckis. Aliás, a pergunta chave para o jogo é: "E se você tivesse acordado em 31 de março de 1964?".

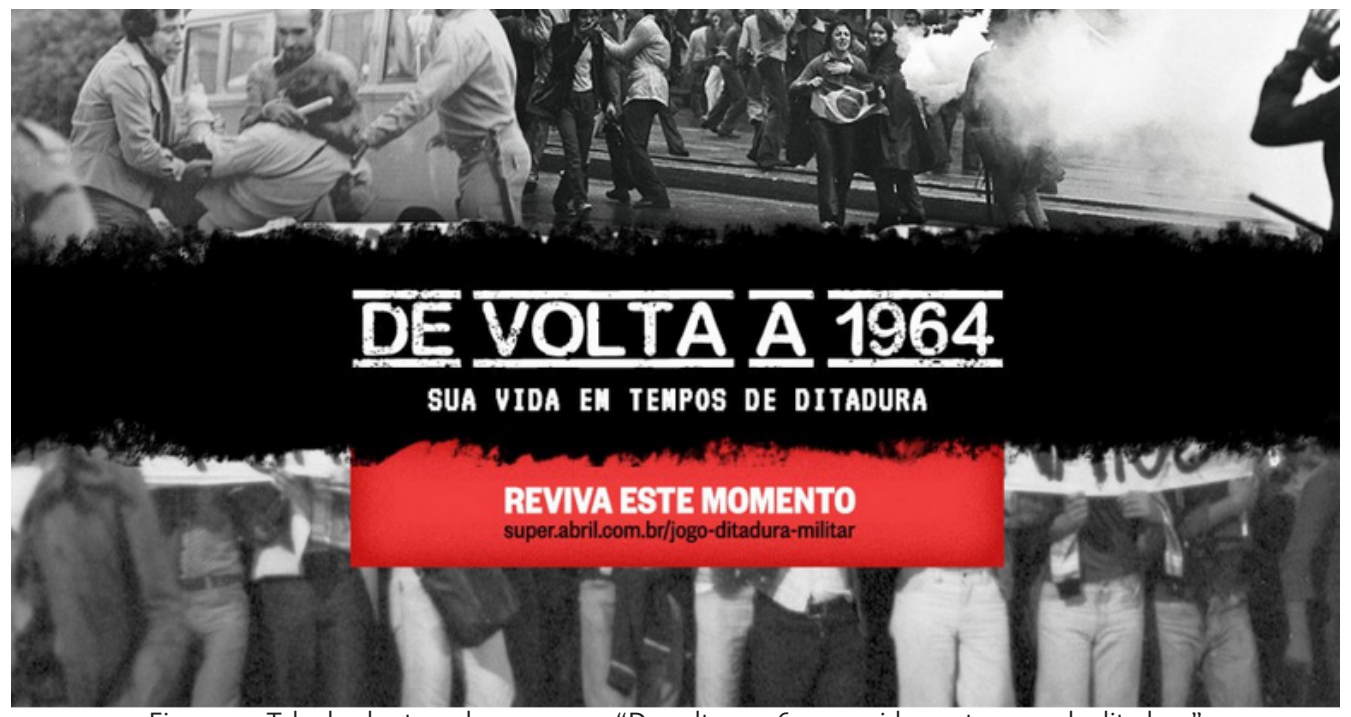

Figura 1 - Tela de abertura do newsgame "De volta a 1964: sua vida em tempos de ditadura"

O Blog da Superinteressante na apresentação do newsgame, assinada por Mariana Nadai, explica:

Um momento de decisões difíceis. Foi com essa premissa que nós, da redação da SUPER, nos propusemos a olhar para os 50 anos do golpe militar brasileiro, comemorado neste $1^{\circ}$ de abril de 2014, e os 21 anos de ditadura que se seguiram a ele. Mas, decidir o enfoque era apenas parte da questão do que seria um especial sobre o período. Era preciso, acima de tudo, saber como apresentar esse momento histórico aos nossos leitores (Blog da Super, 2014) ${ }^{3}$.

O texto de apresentação trata dos 50 anos do golpe militar como um evento a ser comemorado. De acordo com o dicionário Houaiss, o verbo comemorar significa: 1.trazer a lembrança, recordar, memorar; 2.fazer comemoração, realizar cerimônia de evocação; 3.celebrar com festa, festejar. Os significados do termo "comemoração" podem produzir diferentes sentidos, entre eles, o mais comumente encontrado no senso comum se refere a uma situação que merece ser compartilhada com alegria: "comemorar a vitória", "comemorar o aniversário"; menos frequente é o emprego nos casos de morte, tragédias, por exemplo, dificilmente se encontra na mídia as expressões "comemorar a morte", "comemorar a tragédia" ou "comemorar o ataque", e quando isso acontece é visto como uma gafe (ato e/ou palavra impensada, indiscreta, desastrada; indiscrição involuntária, conforme o Houaiss) que merece um pedido de desculpas.

\footnotetext{
${ }^{3}$ Grifo da autora.
} 
Considerando-se o perfil do público da Superinteressante, composto, sobretudo, por jovens entre 15 e 34 anos, nascidos, portanto, a partir de 1980 (o período do golpe foi de 1964 a 1981), que não viveram os anos da ditadura, a expressão "comemorado neste $1^{\circ}$. de abril de 2014" surge como indício da linha editorial adotada. Aliás, em pesquisa no Google, com a frase "comemorado neste $1^{\circ}$ de abril de 2014 ", só surgem seis resultados, todos eles remetem ao Blog da Superinteressante que conferiu à data contornos de alegria, quer tenha sido voluntária ou involuntariamente.

O segundo parágrafo da apresentação explica:

Como faríamos para tratar de uma efeméride que o Brasil inteiro, ou pelo menos todos os meios de comunicação que se prezem, estariam falando? Em tempos da snowfalização da informação, não vou negar que chegamos a pensar em fazer um conteúdo do Golpe com efeito paralaxe. Mas, as nossas raízes falaram mais alto e achamos que esse seria o melhor momento de retomar a produção um modelo que fomos pioneiros no Brasil: o newsgame. Foi assim que nasceu o "De volta a 1964 - Sua vida em tempos de ditadura" (Blog da Super, 2014).

A equipe da Superinteressante faz menção ao artigo Snow Fall do The New York Times, publicado em 2012, que relata os acontecimentos ocorridos em uma tempestade de neve, ganhador do prêmio Pulitzer e o artigo mais visualizado do ano, embora só tenha sido publicado em dezembro. O documentário multimídia deu origem ao termo snowfallization (aportuguesado para snowfallização), derivado do verbo snowfalling, criado a partir do título do artigo, fato que demonstra a importância da linguagem utilizada e a inauguração de uma nova forma de escrever grandes reportagens.

Em 2013, a Folha de S. Paulo lançou a série Tudo Sobre com o especial A Batalha de Belo Monte, e o portal de notícias G1 publicou Buy buy Brasil, ambos seguindo o exemplo de Snow Fall. Os editores da Superinteressante demonstraram interesse em seguir pelo mesmo caminho, razão pela qual "De volta a 1964: sua vida em tempos de ditadura" apresenta uma estrutura híbrida, reunindo elementos do newsgame e dos documentários multimídia.

Um terceiro ponto que merece destaque na apresentação do jogo é a menção ao pouco tempo disponível para o desenvolvimento do jogo: "De lá para cá, foi uma corrida contra o tempo. Tínhamos apenas dois meses para apurar, escrever, desenhar e programar o jogo" (Blog da Super, 2014). Como já foi mencionado, toda a mídia nacional já se organizava desde o segundo semestre de 2013 para tratar dos 50 anos do golpe, o que releva uma decisão tardia da Superinteressante, talvez levada em conta em função da necessidade de se fazer presente à discussão, como os principais veículos de imprensa: "Como faríamos para tratar de uma efeméride que o Brasil inteiro, ou pelo menos todos os meios de comunicação que se prezem, estariam falando?" (Blog da Super, 2014).

Encerrando a apresentação, Mariana Nadai convida os leitores para conhecer o jogo: “E, como a ideia é aprender com o jogo, além de brincar, você também se informa com uma linha do tempo completa, sobre todos os anos da ditadura militar no Brasil. 
Ficou curioso para saber qual seria o seu destino em tempos de ditadura? Não perca mais tempo. Jogue agora!" (Blog da Super, 2014). Mais uma vez percebe-se que o evento foi tratado de forma "leve", procurando associar à experiência de imersão contornos de "brincadeira", fato que, de certa forma, esvazia a complexidade do golpe e de seus desdobramentos, para o país que passou cerca de 20 anos numa ditadura militar. Nas palavras de Bogost, Ferrari \& Schweizer (2010: 10),

Newsgames não são um bálsamo encantado que vai curar os males das organizações de notícias durante a noite. Mas eles representam uma oportunidade real e viável para ajudar os cidadãos a formar crenças e tomar decisões.

Os autores fazem questão de afirmar que os newsgames devem levar sempre em conta a premissa da seriedade. Seus conteúdos devem propiciar ao leitor informação, desenvolvimento de espírito crítico, tomada de posição e aprofundamento em temas relevantes. A ludicidade deve ser o fio condutor no newsgame, mas o aspecto predominante não pode ser o entretenimento.

Os aspectos destacados na apresentação funcionam como pressupostos de toda a estrutura narrativa do newsgame, deixando transparecer o ponto de vista da Abril, sua linha editorial, e uma perspectiva de "desagravo", como se pode verificar ao longo do jogo, como será discutido a seguir.

\section{INTERATIVIDADE, EXPRESSIVIDADE E ENGAJAMENTO NO “DE VOLTA A 1964”}

Interatividade e participação são conceitos que algumas vezes são tomados como sinônimos. Para fins da análise a ser empreendida no escopo deste estudo, os conceitos serão tratados de acordo com as definições propostas por Jenkins (2006):

Interatividade refere-se às formas como as novas tecnologias foram concebidas para serem mais sensíveis ao feedback dos consumidores. Pode-se imaginar diferentes graus de interatividade ativados por diferentes tecnologias de comunicação, que vão desde a televisão, que nos permite apenas mudar de canal, até vídeo games que podem permitir que os consumidores ajam de acordo com o mundo representado [...]. A participação, por outro lado, é moldada pelos protocolos culturais e sociais. Assim, por exemplo, a quantidade de conversa possível em uma sala de cinema é determinada mais pela tolerância do público em diferentes subculturas ou contextos nacionais do que por qualquer propriedade inata do próprio cinema. A participação é mais aberta, menos controlada pelos produtores de mídia e muito mais sob o controle de consumidores de mídia (Jenkins, 2006: 142).

A decupagem do jogo que se segue, será, portanto, pautada tanto nas alternativas propostas pelos produtores do jogo (interatividade) quanto nas possibilidades de engajamento do jogador (participação). 
A estrutura narrativa do jogo é baseada em uma lógica de oposições binárias que vai determinado o caminho a ser seguido até chegar a um desfecho. A cada opção surge uma tela totalizadora, indicando qual percentual de jogadores fez a mesma opção.

Em primeiro lugar, cabe caracterizar o newsgame "De volta a 1964". Bogost, Ferrari \& Schweizer (2010) identificam sete tipos de newsgames: current events, infographics, documentary, puzzles, platforms, literacy e community4. "De volta a 1964: sua vida em tempos de ditadura", encaixa-se na classificação de current event games, assim definidos pelos autores:

Current event games têm poucos requisitos de sistema e ampla distribuição em portais de jogos on-line e em sites de organizações patrocinadoras. Eles são muitas vezes criados em Adobe Flash, uma tecnologia multimídia com acesso quase universal que pode ser embutida diretamente em páginas da Web. Produzir um current event game não apresenta desafios técnicos, mas sim de logística. Seus criadores devem equilibrar timelines com qualidade, decidir se os jogos devem cobrir uma questão política isolada ou uma questão social em curso. Como os current event games são curtos e compactos, têm que trabalhar duro para garantir que seus jogadores entendam imediatamente o contexto e as limitações do tema e da abordagem do jogo. Alguns current event games explicitam os fatos através de texto ou vídeo, ao passo que outros seguem o exemplo de Frasca, na tentativa de influenciar a opinião através do jogo por si só (Bogost, Ferrari \& Schweizer, 2010: 15).

Largamente distribuído, produzido em $\mathrm{HTML}_{5}$, estruturado em torno de decisões logísticas que devem ser tomadas pelo leitor, apresenta uma timeline, vídeos, fotos e demanda, de certa forma, conhecimentos mais amplos do que os inscritos no jogo. Bogost, Ferrari \& Schweizer (2010) subdividem os current event games em: editorial games, tabloid games, e reportage games. "De volta a 1964" é um editorial game: "Editorial games são current event games com um argumento, ou seja, aqueles que tentam de alguma forma persuadir os jogadores" (Bogost, Ferrari \& Schweizer, 2010:15). Os argumentos subjacentes ao "De volta a 1964" serão discutidos ao longo deste paper, conforme forem sendo analisadas as suas estruturas narrativas.

A tela de abertura oferece três possibilidades ao jogador: exibição de um vídeo, "iniciar" e "linha do tempo" (Figura 2). O vídeo, hospedado no Youtube, tem a duração de um minuto e faz uma retrospectiva dos primeiros fatos que levaram a instauração da ditadura militar: são apresentadas fotos (em preto e branco) e manchetes de jornais, animadas, com legendas em vermelho, mostrando de modo dramático o "tempo de decisões difíceis", inclusive com uma foto do jornalista Vladimir Herzog, enforcado em sua cela, nas dependências do Destacamento de Operações de Informações - Centro de Operações de Defesa Interna (DOI-CODI), onde foi preso pelo regime militar. O vídeo é, principalmente, um resumo e um convite para o jogo.

\footnotetext{
${ }_{4}$ Dada a complexidade da tradução dos termos propostos pelos autores optou-se por manter as subdivisões em inglês, como no original.

5 Pelas mesmas razões descritas na nota 9, optou-se por manter as subdivisões em inglês, como no original.
} 


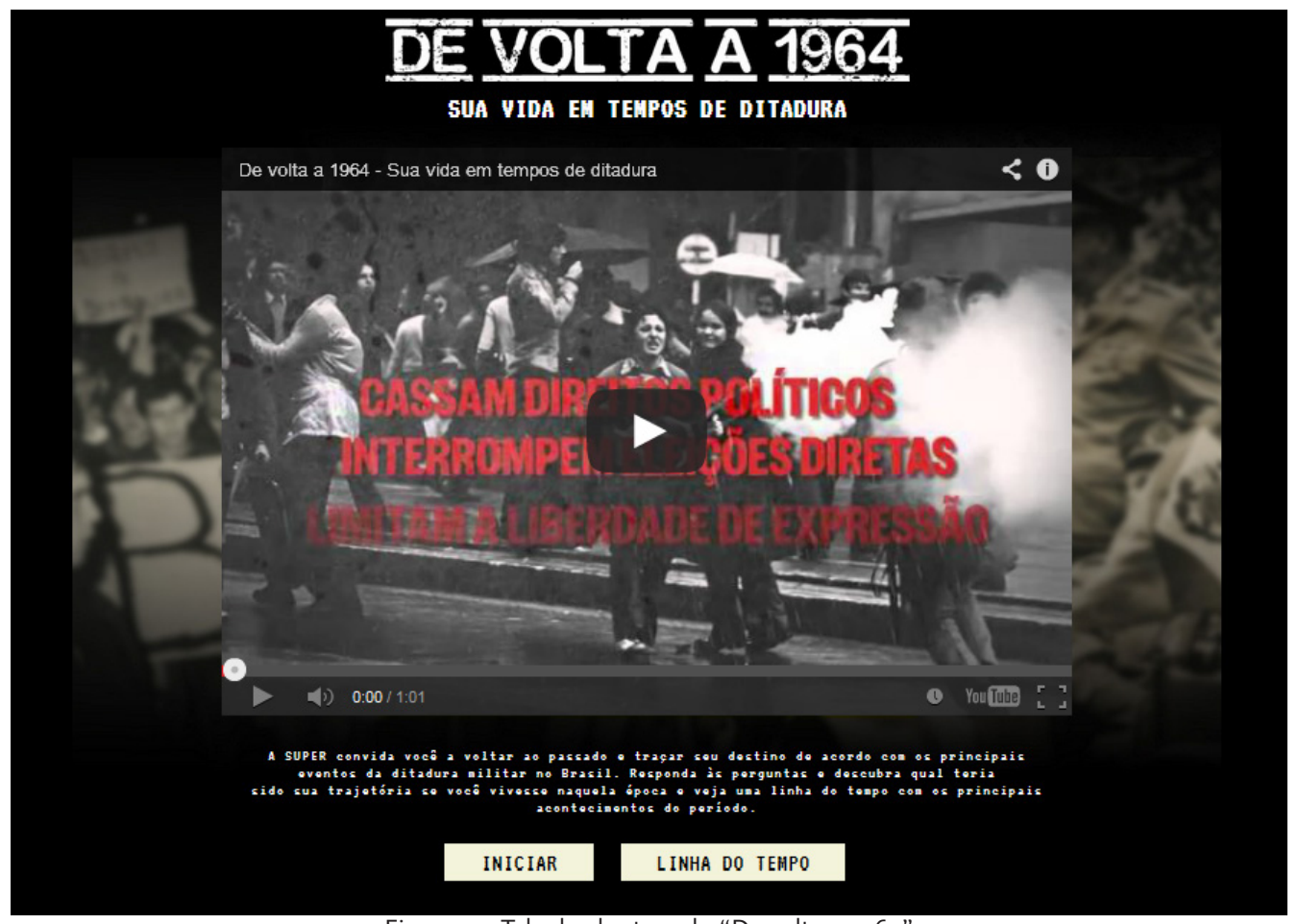

Figura 2 - Tela de abertura do "De volta a 1964"

O vídeo teve 36.693 visualizações (até 30 de setembro de 2014) no canal da Superinteressante no Youtube, com 106 likes e 22 dislikes, um número pouco expressivo considerando-se o número de leitores (como indica a pesquisa já mencionada da ComScore, 2014) e o destaque dado pela mídia para os 50 anos do golpe. O grau de participação foi muito pequeno, apenas 128 internautas que visualizaram o vídeo deram a sua opinião sobre ele $(0,35 \%)$ e $17 \%$ indicaram não ter gostado (dislike).

O fato talvez se deva ao caráter pouco dinâmico do vídeo, composto apenas por imagens animadas de fotos e jornais, com legendas curtas e pontuais, sempre em caixa alta: "Forças armadas tiram do poder o presidente João Goulart", "É instaurada uma ditadura militar no Brasil", "Militares interrompem garantias do governo democrático", "Cassam direitos políticos", "Interrompem eleições diretas", "Limitam a liberdade de expressão". "Opositores são presos, torturados e mortos", "O regime militar acaba 21 anos depois do golpe", Até hoje, crimes da época permanecem sem apuração, julgamento ou punição", "Um período de decisões difíceis", "Reviva este momento". Reproduções de três primeiras páginas, todas do jornal Última Hora (do Rio de Janeiro), com as manchetes "Tropas do Governo na divisa com Minas" (31/03/1964); "Sublevação em Minas para depor Jango" (01/04/1964) e "Ato Institucional foi decretado" (10/04/1964) entremeiam as fotos.

O jornal Última Hora era o único jornal favorável ao presidente deposto, o que denota o ponto de vista editorial da Superinteressante, evitando registrar a posição de outros veículos: o Jornal do Brasil, edição de 1 de abril de 1964 traz a manchete: "S. Paulo adere a Minas e anuncia marcha ao Rio contra Goulart", na mesma data a Folha de S. Paulo publica: "São Paulo parou ontem para defender o regime". Cabe notar que o 
Última Hora foi comprado em 1971 pela empresa Folha da Manhã, a mesma que editava a Folha de S. Paulo.

A "linha do tempo" (Figura 3) tem como data de entrada 1961 e o primeiro evento é a renúncia do então presidente Jânio Quadros e os anos de Governo de João Goulart (Jango) até o golpe de 1964.

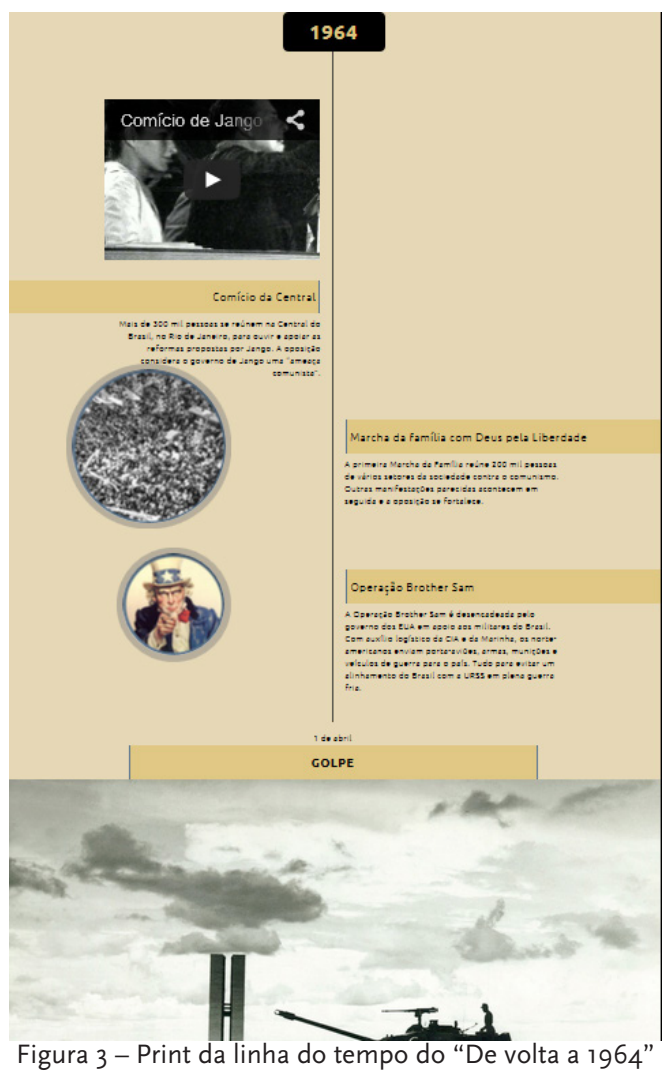

A linha do tempo apresenta fotos e vídeos, mas não há links para outros conteúdos, o que poderia ampliar a capacidade informativa do game. O último evento da linha é a eleição do presidente Tancredo Neves, eleito pelo voto popular, como resultado do movimento "Diretas já", que culminou em 1985.

"Clicando" em "iniciar" o leitor deve cadastrar alguns dados, como explica o newsgame: "Calma, não estamos the monitorando. Seus dados ajudarão a Super a fazer uma matéria sobre o jogo" (Redação da Super, 2014); são inseridos: idade, sexo e Estado (opções válidas para os Estados brasileiros, se alguém reside fora do país não há como registrar o fato).

O próximo passo é ler um texto sobre o contexto mundial, mencionando a Guerra Fria, e surge um convite para que o jogador escolha se aceita ou não o convite para participar da "Marcha da Família": "sim" ou "não". Cada escolha determina um percurso diferente, que vai gerando novas opções, até chegar a conclusão do jogo. Para quem seleciona "sim" (o newsgame informa que $36 \%$ dos jogadores tomam essa decisão) são oferecidas duas novas possibilidades: "ir ao encontro" ou "ficar em casa".

Para quem decide "ir ao encontro" ( $56 \%$ dos jogadores o fazem) a tarefa seguinte será escolher se "desce do ônibus" ou "volta para casa" ao visualizar polícias e militantes de esquerda próximos à faculdade. 
O jogo de oposições binárias prossegue. Para quem "desce do ônibus" e considerando-se a criação do Serviço Nacional de Informações - SNI - é feito um convite para participar de uma discussão sobre o movimento de Resistência ao Regime Militar (82\% participam do encontro).

A narrativa discorre sobre o contexto, sendo que as saídas são: "Luta de Massas" ou "Luta Armada". Não existem informações que subsidiem a decisão: não há explicações sobre o que é luta de massas, nem as implicações acerca da luta armada, mesmo assim, $24 \%$ dos jogadores seguiriam a segunda opção, lutando ao lado da guerrilha liderada por Carlos Marighella.

Surge então um aviso: "Atenção: Para esta situação você terá apenas 60 segundos para responder (caso não responda no tempo determinado escolheremos uma opção para você)" (Redação da Super, 2014). Após ler um breve texto explicativo sobre a guerriIha rural, o jogador deve decidir se "participa" ou "não participa" e $73 \%$ segue em frente.

O último quadro apresenta o resultado geral do percurso: " $7 \%$ das pessoas que responderam tiveram o mesmo desfecho que você" (Redação da Super, 2014). O desfecho para quem decidiu aceitar a todos os convites é então apresentado:

QUE PAÍS É ESTE? Você decide participar da guerrilha rural e segue viagem para um lugar próximo às margens do rio Araguaia, no Pará. Mas essa localização é descoberta pelo Exército e você é brutalmente assassinado. A onda de violência atinge também os moradores da região. Oficiais cortam a cabeça e as mãos das vítimas e as deixam em sacos para identificação pelo Exército. Segundo estimativa dos militares, mais de 80 guerrilheiros morrem (Redação da Super, 2014) ${ }^{6}$.

A tela apresenta o desenho estilizado de um jovem assassinado (Figura 4).

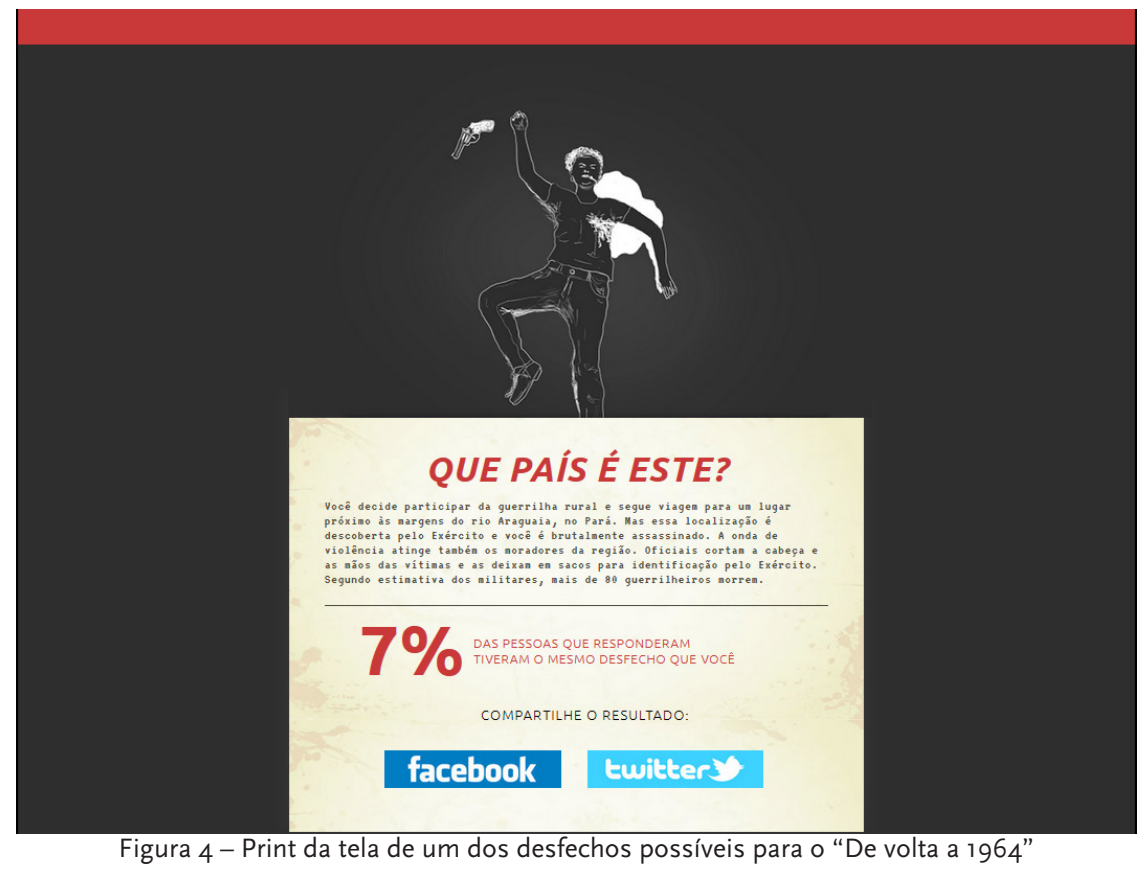

\footnotetext{
${ }^{6}$ Grifo no original.
} 
O jogo leva a outros desfechos similares (Figura 5), fazendo perceber que, basicamente existem dois caminhos, um tomado por aqueles que demonstram maior engajamento político e outros que preferem se distanciar de tais questões.

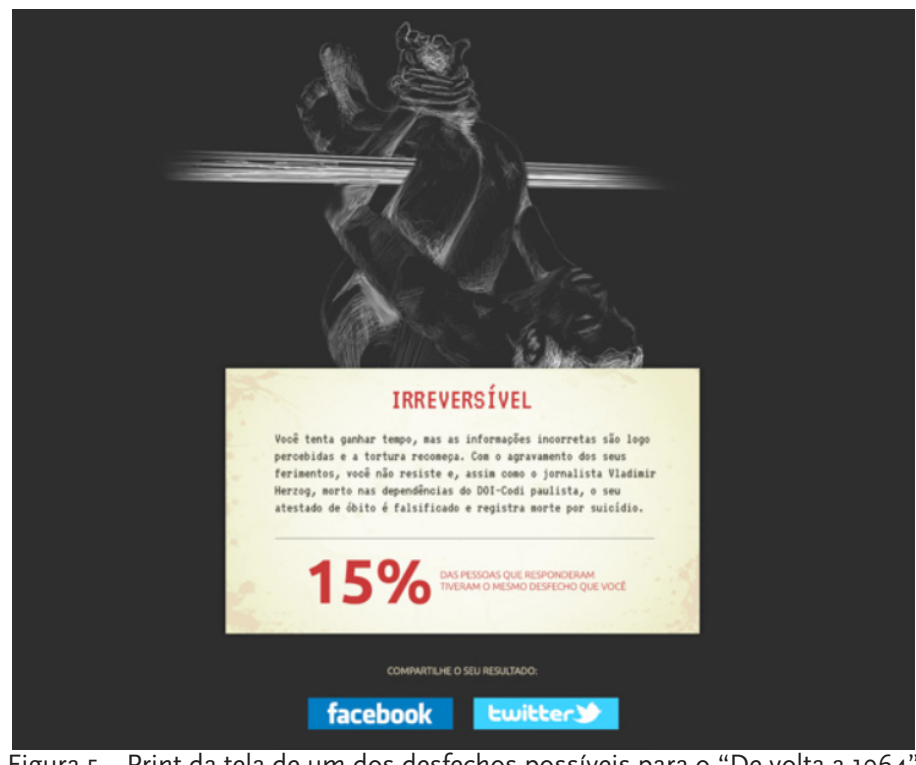

Figura 5 - Print da tela de um dos desfechos possíveis para o "De volta a 1964"

O percurso descrito representa um dos movimentos possíveis a partir das interações disponíveis. De acordo com Sims, podem ser identificados três tipos de interatividade através da web:

Interação linear: seguir e retroceder; Interação hierárquica: utilizando menus; - Interatividade de suporte: com tópicos de auxílio e apresentação de tutoriais e caminhos pré-determinados a seguir; Interatividade de simulação: o usuário relaciona ações que são possíveis na realidade; Interatividade de hiperlinks: o usuário tem à disposição caminhos para navegar, podendo se dirigir para um caminho diferente do anterior (Sims citado por Almeida, 2003: 8).

Com base nessa tipificação, a estrutura narrativa do "De volta a 1964" encaixa-se nos tipos: interatividade de simulação, pois o jogador deve se colocar no lugar de alguém que enfrenta os desdobramentos do golpe militar de 1964 e interatividade de hiperlinks, na medida em que escolhe o caminho a seguir. Entretanto, o grau de interatividade é baixo, já que as opções se resumem ao longo do jogo a "ir" ou "não ir", "participar" ou "não participar", "aceitar" ou "não aceitar".

O newsgame é montado numa estrutura hipertextual, da mesma forma que outros jogos da Superinteressante, como o CSI - A Ciência contra o crime, o que nem sempre favorece a interatividade e a participação. Para Primo (2003: 3) "Se antes participação rimava com discussão, hoje participar rima com apontar-clicar. Nesse cenário, quanto mais "clicável" é um site, mais interativo ele será considerado (mesmo que todas as reações dos links e botões já estejam determinadas na programação/previsão)", nesse sentido "De volta a 1964" quase não é "clicável”, já que eles aparecem apenas sete vezes (no percurso descrito) depois de iniciado o jogo. 
Pensando com Sicart (2008: 32), os newsgames são: «Jogos sérios, projetados para ilustrar um aspecto específico e concreto da notícia por meio da retórica processual, com o objetivo de participar do debate público", assim, os fatos tratados pelo "De volta a 1964" poderiam ter merecido um melhor tratamento, ampliando as possibilidades de interação e participação através da discussão de questões significativas para o país. No início deste texto, mencionou-se o fato do jogo ter sido feito muito rapidamente (mesmo considerando-se que os newsgames em geral são feitos de modo acelerado), parece ter faltado à equipe de desenvolvedores mais tempo para estabelecer outras conexões.

Existe um vasto material sobre o golpe de 1964 produzido, inclusive pela própria Editora Abril, que não foi aproveitado, entre eles destacam-se vídeos, mapas, documentos, sem contar documentos atuais e iniciativas ligadas ao momento histórico que o país enfrenta. A frase "De volta a 1964: sua vida em tempos de ditadura", pesquisada no Google resulta em apenas 357 resultados, quase todos limitados a comentar o lançamento do game, o que dá indícios de baixa participação. A matéria mencionada no início do jogo ainda não foi divulgada. Como o newsgame foi enquadrado na categoria editorial games, é preciso ter em mente alguns aspectos desse tipo de estrutura para prosseguir com a análise.

$\mathrm{Na}$ verdade, Ferrari (2009) diferencia newsgames de editorial games:

A diferença entre "newsgame" e "editorial game" é distorcida. Basicamente, a nossa sugestão é que a maioria dos jogos chamados "newsgames" não têm as mesmas intenções ou objetivos de relatos tradicionais como a "notícia", mas sim as mesmas intenções do artigo de opinião: ou seja, persuadir; portanto, devemos rotular estes artigos de opinião digitais como "editoriais" ao invés de "notícias". A maioria das pessoas, provavelmente, está inclinada a ignorar a possível distinção, porque não parece haver prova suficiente de que precisamos de uma; em primeiro lugar (nós não podemos apontar a que um newsgame "propriamente jornalístico" seria semelhante, como Paolo Pedercini já fez). No final iremos (esperamos) ter uma melhor compreensão da relação entre editorial e notícia, bem como uma compreensão mais firme da retórica processual usada em editorial games (Ferrari, 2009: 1).

"De volta para 1964" mostra-se muito mais próximo de um editorial game do que de um newsgame, uma vez que o foco não está nas notícias, estas aparecem de modo a costurar a narrativa, a informação aparece sintetizada, amarrada a um ponto de vista, como percebe-se, por exemplo, em um dos possíveis caminhos do jogo surge a seguinte questão: "Você gosta do seu emprego, apesar de não ganhar tão bem assim. Eis que um amigo te indica para uma vaga numa grande empresa, onde você terá um salário mais alto para fazer um serviço bem mais chato e burocrático. O que você prefere?" (Redação da Super, 2014); qual o objetivo dessa pergunta? Em que esse fato se relaciona especificamente com o golpe? Fica evidente a necessidade de encontrar um desfecho condizente com o ponto de vista desenvolvido. Quem permanece no emprego recebe a seguinte mensagem: 
ALEGRIA, ALEGRIA Você decide priorizar um estilo de vida mais simples e continua trabalhando no mesmo emprego por muitos anos. Apesar de se informar sobre o que acontece no Brasil, você não é afetado diretamente pelas mãos de ferro do regime. Depois da redemocratização do Brasil, você se afasta ainda mais da política e costuma anular seus votos (Redação da Super, 2014).

O resultado indica que uma vida de apatia política, pouco engajamento e sem grandes ambições leva a uma vida feliz (Figura 6). O discurso contido no trecho destacado mostra a distância entre a narrativa do jogo e a narrativa dos fatos, como se verifica na passagem "Apesar de se informar sobre o que acontece no Brasil, você não é afetado diretamente pelas mãos de ferro do regime", que faz parecer que o jogador não vive no Brasil ou que é possível viver numa ditadura militar sem ser por ela afetado.

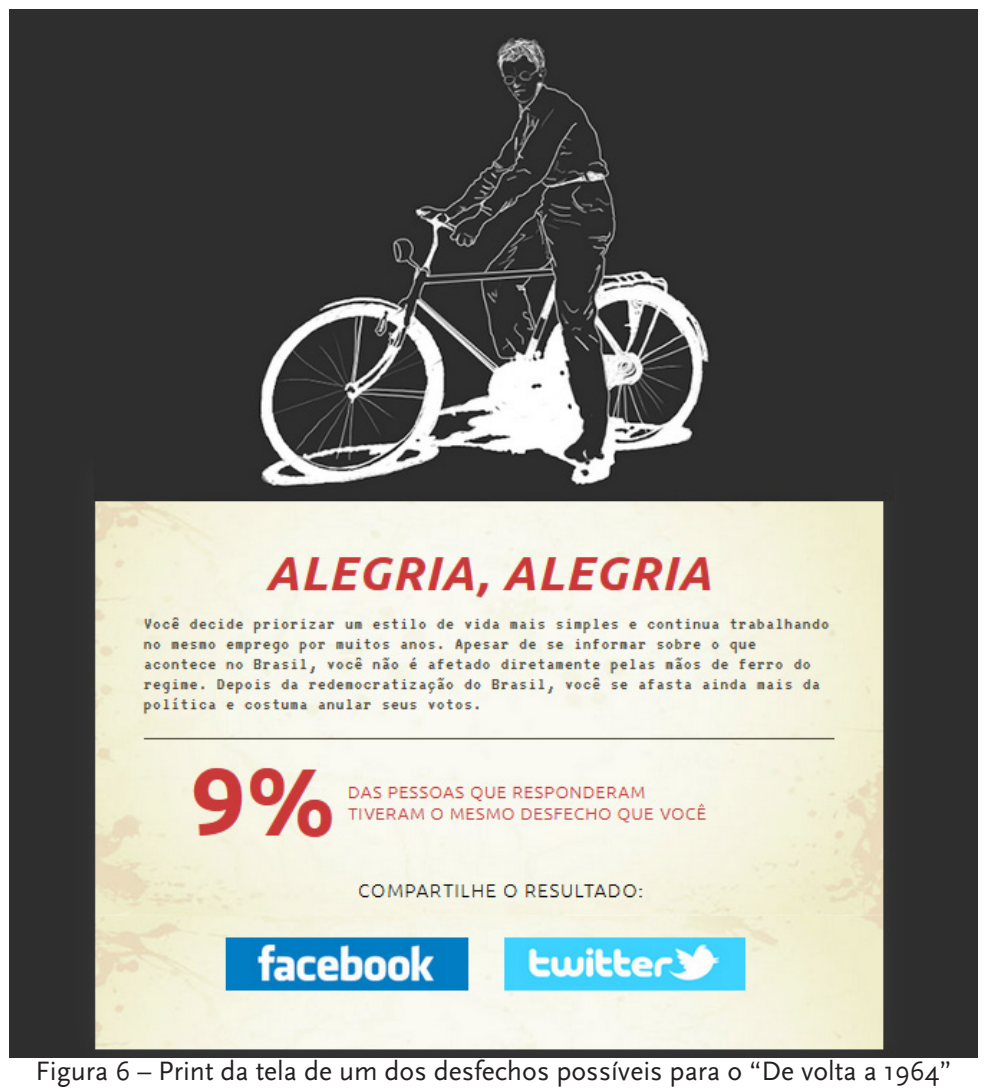

Para o jogador que optou por "mudar de emprego", a próxima jogada é decidir o que fazer com o bônus recebido: "Sua carreira profissional deslanchou e agora você faz parte de uma parcela da população que não precisa se preocupar com dinheiro e que passa ilesa pelos anos mais duros da ditadura. Você recebe uma bonificação de final de ano da empresa. O que você quer fazer com o dinheiro?" (Redação da Super, 2014), e surgem duas possibilidades: "Dar entrada numa casa" ou "viajar com a família". Qualquer que seja a escolha a próxima pergunta é a mesma: "A ditadura militar nunca te afetou de maneira negativa. Agora, seu filho adolescente pediu permissão para participar de uma das manifestações contra o regime. O que você faz?" (Redação da Super, 2014). 
Essa etapa do newsgame poderia ser suprimida, já que ambas as respostas levam para o mesmo lugar. Mais uma vez o fio narrativo sai do contexto das notícias e assume um caráter editorial e, mais, vai se descontextualizando, deixando o golpe para trás. A questão do golpe militar de 1964 vai sendo enfraquecida diante de aspectos triviais de todo cotidiano e não somente daquele momento.

\section{CONSIDERAÇÕES FINAIS}

Ao contrário de alguns temas típicos da cultura contemporânea, os estudos sobre os newsgames apresentam o fenômeno com uma literatura densa e cuidadosa. Os escritos de Frasca (2001), Bogots (2008), Bogost, Ferrari \& Schweizer (2010), lurgel \& Zagalo (2009), Ferrari (2009), Gonçalves \& Zagalo (2010) Zagalo (2012), Sicart (2008), autores que serviram de embasamento para a análise aqui apresentada, reúnem uma série de elementos que permitem contextualizar os jogos de notícias e relacioná-los com outros produtos culturais, apresentando suas potencialidades e limites, as perspectivas futuras e os desdobramentos desse tipo de estrutura narrativa no ambiente midiático.

Um primeiro ponto a destacar é a retomada do pensamento de Huizinga (1938: I), para quem "É no jogo e pelo jogo que a civilização surge e se desenvolve" (prefácio), conferindo músculos para se pensar os newsgames dentro da perspectiva do autor, que trata o jogo como um assunto sério, que "distingue e tipifica tudo o que acontece no mundo" (Huizinga, 1938: I).

Outro aspecto importante é o estudo das formas narrativas, da linguagem e da retórica, o que confere aos newsgames um horizonte de estudos mais largo e consistente, inserindo-o sincrônica e diacronicamente no eixo das produções culturais cujo suporte é a internet.

Um terceiro ponto que enriquece as pesquisas sobre o tema é o fato de que muitos dos estudiosos são também desenvolvedores de games, ou seja, conhecem a lógica da programação, o que é ou não possível fazer, até que ponto um newsgame é tolhido pela complexidade do código ou pelas limitações tecnológicas.

Os estudos mencionados dão conta de que os newsgames disseminaram-se rapidamente e que as perspectivas de utilização do formato se ampliam, aprimorando, a cada dia, a experiência do jogador. Num ambiente de convergência digital (Jenkins, 2010) em que as formas tradicionais de comunicação enfrentam a crise gerada pelo consumo de conteúdo produzido e distribuído pela rede mundial de computadores, as empresas jornalísticas veem nos newsgames uma das alternativas possíveis para atrair o leitor.

A experiência da revista Superinteressante, da Editora Abril, merece destaque, tornando-se pioneira do Brasil e incentivando o investimento em newsgames, ao mesmo tempo em que vai formando um público receptível e este tipo de linguagem.

"De volta a 1964: sua vida em tempos de ditadura", o newsgame aqui analisado, possui um baixo grau de interatividade, podendo ser classificado como um game reativo, cuja estrutura se fundamenta em poucas alternativas preestabelecidas, que várias vezes se entrecruzam, independente do caminho escolhido. Sua expressividade, derivada 
da união entre uma narrativa jornalística e o caráter lúdico do jogo, prescinde de mais elementos para ampliar a capacidade de imersão do game, conferindo-lhe, dessa forma, mais tensão, dinâmica e aproximação da realidade. Talvez em função desses dois aspectos, o nível de engajamento também tenha sido pequeno, nem mesmo os links para compartilhar os resultados via Twitter ou Facebook conseguiram fomentar o debate sobre o jogo e sobre as questões a ele subjacentes.

O tema gerador do game, os 50 anos do golpe militar no Brasil, tornou-se espinhoso para os desenvolvedores, gerando alguns problemas éticos (como "comemorar os 50 anos do golpe") e textuais (a coerência e a coesão são comprometidas em alguns momentos, quanto às questões centrais distanciam-se no objeto do jogo). Ao contrário de outros newsgames desenvolvidos pela Superinteressante, que se destacaram inclusive internacionalmente, o "De volta a 1964", aqui classificado como um editorial game, ficou preso na tentativa de apresentar um ponto de vista isento e deixar para o leitor/jogador a missão de trilhar seu próprio percurso. Os newsgames, como ressalta a literatura pesquisada, precisam encontrar a exata medida entre o lúdico e jornalístico.

\section{REFERÊNCIAS}

Almeida, C. (2003) “Novas Tecnologias e Interatividade: além das interações mediadas", Data Grama Zero, 4 (4):1-12, [em linha], disponível em: http://www.dgz.org.br/ago03/Art_01.htm, acedido em 05/09/2014.

Blog da Super (2014) De volta a 1964: sua vida em tempos de ditadura, [em linha], disponível em http://super. abril.com.br/blogs/superblog/de-volta-a-1964-sua-vida-em-tempos-de-ditadura-por-dentro-do-jogo/, acedido em 05/9/2014.

Bogost, I. (2007) Persuasive Games: The Expressive Power of Videogames, Cambridge: The MIT Press.

Bogost, I. (2008) "The Rhetoric of Video Games", The Ecology of Games: Connecting Youth, Games, and Learning. MacArthur Foundation Series on Digital Media and Learning. Cambridge, MA: The MIT Press. 117-140 [em linha], disponível em http://nau.edu/CAL/Interdisciplinary-Writing-Program/_Forms/ Rhetoric VideoGames_ Bogost/, acedido em 05/9/2014.

Bogost, I.; Ferrari, S. \& Schweizer B. (2010) Newsgames: Journalism at Play, Cambridge: MIT Press.

ComScore (2014) Dados [em linha] disponível em http://publicidade.abril.com.br/marcas/44/internet/ informacoes-gerais, acedido em 08/9/2014.

Déda, T. \& Zagalo, N. (2010) "Newsgames e Social Games como ferramentas atuantes em novos modelos comunicativos de engajamento", Videojogos, 129-134 [em linha], disponível em https://www.academia. edu/709340/Newsgames_e_Social_Games_como_ferramentas_atuantes_em_novos_modelos_ comunicativos_de_engajamento, acedido em 05/9/2014.

Ferrari, S. (2009): Newsgame, or Editorial Game? [em linha] disponível em http://simonferrari. com/2009/06/02/sicartfrasca/, acedido em: 05/9/2014.

Frasca, G. (2003) Simulation versus Narrative: Introduction to Ludology, New York, Routledge.

Gonçalves, A. \& Zagalo, N. (2010) "Entre a realidade e a virtualidade", Proceedings do SBGames [em linha] disponível em https://www.academia.edu/2818922/Entre_a_realidade_ea_virtualidade, acedido em 05/9/2014. 
Huizinga, J. (1938) Homo Ludens - O Jogo como Elemento da Cultura, São Paulo: Perspectiva (1971).

Jenkins, H. (2006) Convergence Culture Where Old and New Media Collide, New York: New York University Press.

lurgel, I. A., Zagalo, N. \& Petta, P. (eds) (2009) Interactive Storytelling, Lecture Notes in Computer Science, Heidelberg: Springer Berlin, 234-245.

Machado, A. (1990) A Arte do Vídeo, São Paulo, Brasiliense.

Primo, A. (2003) "Quão interativo é o hipertexto: da interface potencial à escrita coletiva" Fronteiras - Estudos Midiáticos, 5 (2): 125-142 [em linha], disponível em http://www.ufrgs.br/limc/PDFs/quao_interativo_ hipertexto.pdf, acedido em 05/9/2014.

Blog da Super (2014) "De volta a 1964: sua vida em tempos de ditadura. Newsgame" Revista Superinteressante [em linha], disponível em http://super.abril.com.br/jogo-ditadura-militar/, acedido em 05/9/2014.

Sicart, M. (2008) "Newsgames: Theory and Design", International Conference on Entertainment Computing Pittsburgh, PA, 27-33 [em linha], disponível em http://link.springer.com/chapter/10.1007\%2F978-3-54089222-9_4\#page-1, acedido em 05/9/2014.

\section{LUDOGRAFIA}

Editora Abril (2014), De volta a 1964: sua vida em tempos de ditadura $®$

Editora Abril (2013), CSI — A ciência contra o crime $®$

Editora Abril (2013), Filosofighters $\mathbb{R}$

Editora Abril (2013), O jogo da Máfia $®$

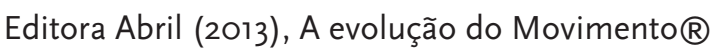

Editora Abril (2013), Corrida Eleitoral $\mathbb{R}$

Folha de S. Paulo (2013), A Batalha de Belo Monte $\mathbb{R}$

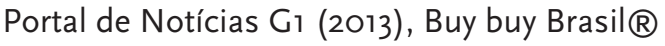

The New York Times (2012), Snow Fall $®$

\section{Nota BiográficA}

Lilian Cristina Monteiro França. Doutora em Comunicação e Semiótica pela PUCSP. Pós-Doutora em História da Arte pelo IFCH/UNICAMP. Professora do Departamento de Comunicação Social e dos Programas de Mestrado em Comunicação e Letras da Universidade Federal de Sergipe. Desenvolve projeto conjunto com o Hunter College/ City University of New York, intitulado "Subjugated knowledge - permitting narratives to emerge". Autora dos livros "Caos Espaço Educação" (Annablume), "Da geometria eucliana a geometria fractal - um estudo sobre história da arte» (Educ) e «Imagens e números»(Edufs), entre outros. 
E-mail: liliancmfranca@uol.com.br

Departamento de Comunicação Social. Universidade Federal de Sergipe. Campus Universitário "Prof. José Aloísio de Campos". Rodovia Marechal Rondon, s/n. Rosa Elze. 49.100-000. São Cristóvão - Sergipe - Brasil

* Submetido: 30-11-2014

* Aceite: 15-3-2015 